\title{
Breeding, rearing and raising the red-bellied toad Bombina bombina in the laboratory
}

\author{
Otto Kinne*, Jens Kunert, Waldemar Zimmermann
}

Inter-Research and International Ecology Institute Nordbünte 21 \& 23, 21385 Oldendorf/Luhe, Germany

\begin{abstract}
We have studied the ecology and biology of the highly endangered ancient amphibian Bombina bombina (Linneus 1761) — not least in order to encourage scientists, lay people and politicians to support this toad in its fight for survival. Hence our report does not strictly adhere to the format of a publication intended solely for scientists. We present here information on breeding, rearing and raising; on the toad's ecological requirements; on problems of laboratory maintenance, and on possibilities of rebuilding extinct wild populations.
\end{abstract}

KEY WORDS: Ecology and biology of Bombina bombina $\cdot$ Cultivation $\cdot$ Production $\cdot$ Raising $\cdot$ Release - Resale or republication not permitted without written consent of the publisher

\section{How it all began (Otto Kinne)}

My first encounter with the fire-bellied toad Bombina bombina dates back to 1949. Studying at the University of Kiel, Germany, I participated in a zoological excursion headed by my academic teacher Professor Adolf Remane, an internationally renowned scholar in the fields of ecology, taxonomy, phylogeny and morphology. He was well-known for his profound knowledge of local animals and plants.

The excursion was fascinating. After demonstrating to us students a variety of different life forms in their natural habitat, Remane suddenly stopped, placed a finger over his lips and whispered: 'And now I am going to show you something very fine (etwas ganz Feines). Please be as quiet as possible and enjoy with me rare and highly endangered toads - animals which you will no longer be able to see when you are my age.' He tip-toed towards a pond. After reaching it, we stood around our teacher-and did not see any toad at all. After several minutes of silent waiting, about 25 toads surfaced one after the other. And yet another 5 minutes later the males among them began a melodic concert of oop-oop-oop-oops. We listened in awe.

Some 32 years later, in spring 1981, my wife Helga and I moved away from Hamburg and bought a house in Oldendorf/Luhe with grounds bordering on the river Luhe. To my great surprise, during one of my Luhevalley excursions I observed a fire-bellied toad floating

\footnotetext{
*Email: kinne@int-res.com. Fax: +49 41328883
}

(ㅇ) Inter-Research $2004 \cdot$ www.int-res.com on the water surface of a ditch. When I stepped closer it quickly disappeared. I never saw it again.

It was in 1989 that I decided to assist Bombina bombina in its difficult fight against extinction. I planned to breed the toad, to rear and raise offspring and to release juveniles into newly aquired and toadspecifically modified sections of the Luhe valley (Kinne et al. 2003b, Fig. 1). It took about 3 years to build pools, ponds and ditches, over-wintering quarters and field laboratories.

Where can you get Bombina bombina? They are not for sale in shops. Any zoo shop that would dare to sell fire-bellied toads risks being fined or closed. And you cannot collect the toad in nature. In Germany, B. bombina are protected by law. It took some efforts to locate a man who was officially permitted by government ruling to sell toads raised in his own terrarium or pond to people who can demonstrate the ability to keep them under adequate conditions. I bought from him some adults and received a written purchase document stamped by a government official. I still keep that document in a lab drawer.

After the toads were accomodated in a large terrarium with land and water sections, the males began to call. Older than Professor Remane at the time he predicted the extinction of Bombina bombina, I was deeply moved to hear their oop-oop-oop-oop concert again, and I remained sitting in front of my terrarium for hours.

\footnotetext{
First published December 5, 2003, under INTERRESEARCH REPORTS as Rept 3
} 


\section{INTRODUCTION}

The red-bellied toad Bombina bombina (Linneus 1761) (German: Rotbauchunke, French: Sonneur à ventre de feu) is one of the oldest living forms of life on earth. Within the last decades, the explosive development of our own species Homo sapiens has made the toad also one of the most highly endangered forms of life.

Not least in central and east Europe many amphibians suffer increasingly from changes in their environment that are in essence consequences of human activities. Populations of toads, newts and frogs shrink or disappear with increasing speed. It is high time to sound a world-wide alarm. We must protect the amphibians and rebuild sufficient numbers and sizes of their habitat areas and thus enhance the amphibians' chances for surviving human impacts.

For 10 years we have worked hard to produce the knowledge required for establishing a self sustaining field population of Bombina bombina. Studies on the toad's ecology and biology provided information on the environmental conditions needed for development, reproduction and population survival. Appropriate moist-meadow land was bought and prepared for serving as a living area for $B$. bombina: 'Inter-Research Land' or 'IR land' (Kinne et al. 2003, Fig.1). IR Land comprises some 5.5 hectares of the valley of the river Luhe (North Germany). In IR Land we built pools, ponds and ditches and 2 small field laboratories (Fig. 1) and we demonstrated what can be done in support of

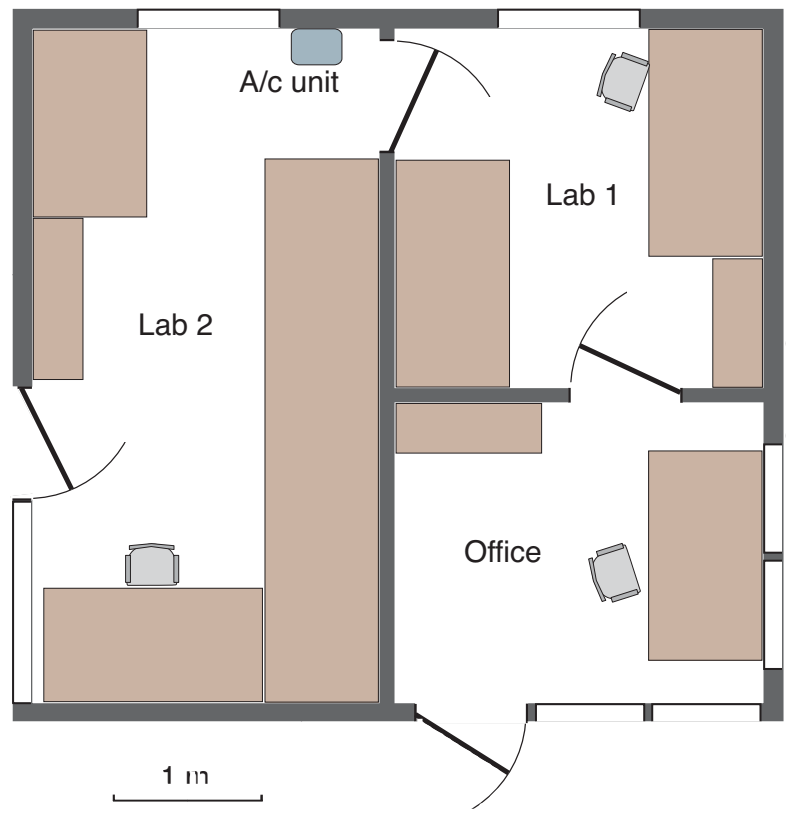

Fig. 1. Field laboratories. Floor plan endangered life by initiatives that do not require much money - but much enthusiasm and dedication.

In contrast, global support of endangered life requires enormous efforts and - most importantly $-a$ new concept of ethics: Eco-Ethics* (Kinne 1988, 2002, 2003, EEIU Brochures, www.int-res.com).

\section{MATERIAI}

Taxonomically, Bombina bombina belongs to the Amphibia - an animal class comprising the first vertebrates that left the ocean and conquered the land. Amphibians are the ancestors of reptiles, birds and mammals (including our own species Homo sapiens). They evolved from lobe-fin fishes (Crossopterygii) or lungfishes (Dipnoi) more than 400 million years ago. Like $B$. bombina most amphibians live both in water and on land ('amphi' from Greek: 'both'). The majority of the ca. 4800 living amphibian species (frogs, toads, salamanders, newts, caecilians) are found in the tropics. Frogs and toads (Order Anura) form the largest group of the Amphibia.

\section{GENERAL ASPECTS}

Red-bellied toads Bombina bombina have been recorded in north and east Europe and in southwest Asia. Published details on their distribution do not sufficiently take into account the last few decades in which numerous local populations have become extinct. The toads live predominantly in (largely predator-free) low-land meadow areas with plant inhabited small pools, ponds or ditches. They prefer clear, non-flowing, calm waters. In the northern valleys of the river Elbe (Germany) B. bombina spend the warm season in permanent water bodies (Wilkens 1979; see also Engel 1985). In IR Land the toads also occupy shallow ground depressions that contain nonpermanent water bodies. Overall, the toad's habitats are characterised by unstable environmental conditions.

We hypothesise that such unstable environmental conditions are not really preferred by Bombina bombina but represent refuges from heavy predation (especially by insects, leeches, fishes): B. bombina can

*Eco-ethics emphasises the significance of healthy ecosystems for life on earth. It is represented by the Eco-Ethics International Union (EEIU) with its rapidly growing numbers of Local Components (Chapters, Youth Groups, Task Forces), Fellows and Members in all parts of the planet (www.eeiu.org), and continually further developed in the Union's publication organ Ethics in Science and Environmental Politics (ESEP; www.esep.de). 
live and reproduce perfectly well in the stable, predator-free environments provided in our laboratories and in a field cage. For us $B$. bombina is an example of a life form which nature does not permit to exist under conditions that, in terms of its physiological potential, would be optimal. Its low capacity to cope with predation and competition forces the toad to retreat to less comfortable conditions which it can tolerate due to its high capacity of coping with unstable, rapidly changing environments. Such environments exclude most of the toad's predators and several of its competitors. Another example of such 'retreat' is the hydroid Cordylophora caspia, which has an experimentally demonstrated salinity optimum of about $15 \% \mathrm{~S}$ (maximum growth and reproductive rates) but lives in very low salinities in which its major predators cannot exist (Kinne 1956, 1958). A third example is the brine shrimp Artemia salina; it uses the same strategy: retreat to extreme environmental conditions (very high salinities) that are lethal to its predators. Accordingly, all three, B. bombina, C. caspia and A. salina, exist in environments they do not 'like' but can tolerate and thus escape their predators. For a comprehensive treatment on predation and the responses to it by offshore animals consult Gliwicz (2003).

As other amphibians of the order Anura (frogs, toads) Bombina bombina copulate with the male riding on the female, firmly clasping her with his arms (copulatory embrace or amplexus lumbaris). As soon as the female releases eggs, the male distributes sperm over them and thus initiates fertilisation.

Statistics. Throughout our work we have avoided statistical analyses that would require exposure of eggs, tadpoles or toads to life-endangering stress or that would involve killing them, e.g. experiments on heat, cold or pollutant tolerance. While sacrificing animals for detailed statistics may have yielded more exact data, we consider our statements to be sound approximations. Our statements are based on situations that happened as something unintended, for example, extreme over-heating due to sun exposure or extreme low temperatures due to thermal control failures. We treated our animals with care and respect; our ethical codes were not compromised.

Diseases. In our breeding, rearing and raising experiments Bombina bombina remained astonishingly free of diseases. In particular, there was no or negligible mortality in adults. However, in tadpoles and juveniles 2 abnormal phenomena required attention: (1) In 1999 about $40 \%$ of a tadpole group (35 individuals) developed, at total body lengths (snout tip to tail end) of ca. $2.5 \mathrm{~cm}$, white spots on their tails. The round spots (up to ca.1.2 $\mathrm{mm}$ in diameter) rapidly grew in number (up to 45 per tadpole). They were most frequent along the outer tail margins. The spots did not have significantly negative effects (e.g. on growth). They disappeared shortly before or during metamorphosis. We called this phenomenon 'White Spot Tail Disease' (WSTD). Similar cases of WSTD were observed in 2001 and 2002. (2) In 1998 one group of 72 juveniles exhibited what we called 'Big Belly Disease' (BBD). The disease appeared suddenly. Within a few days the bellies about doubled in size. The sick juveniles had increasingly difficulties in moving about. Finally they could no longer creep or jump. About $85 \%$ of the juveniles died within 12 days after we first noticed BBD. We attempted to determine cause and kind of WSTD and BBD but our technical means turned out to be insufficient. Isolation and exposure experiments revealed that both diseases are contagious. We assume that WSTD is caused by a fungus. One of us (O.K.) dissected a few juveniles suffering from BBD shortly after they had died and found hundreds of rapidly moving flagellates in their stomach area. Whether or not they had caused the disease or whether their presence was a consequence of BBD remains unknown.

While we have not found reports on diseases affecting Bombina bombina in the literature, there exist numerous papers referring to infectious diseaes in related amphibians, especially due to viruses: Darlington et al. (1966), Granoff et al. (1966), Clark et al. (1968, 1969), Willis et al. (1977), Granoff (1989), Speare (1990), Fijan et al. (1991), Speare et al. (1991), Speare \& Smith (1992), Cunningham et al. (1993), Hengstberger et al. (1993), Drury et al. (1995), Whittington \& Speare (1996), Ahne et al. (1997), Zupanovic et al. (1998a,b), Pascolini et al. (2003).

Woodhams et al. (2003) studied chytridiomycosis, caused by the chytrid fungus Batrachochytrium dendrobatidis. This disease is assumed to have significantly contributed to the alarming declines of amphibian populations in Australia and Central America (Berger et al. 1998, Bradley et al 2002). Woodhams et al. were able to cure the disease by temperature elevation: Exposing frogs Litoria chloris to $37^{\circ} \mathrm{C}$ 'for less than $16 \mathrm{~h}$ can clear them of the pathogens and prevent the development of chitridiomycosis' (p. 67).

Sera containing antibodies against 'rana viruses' have been detected in giant toads Bufo marinus in Australia and Venezuela. Zupanovic et al. (1998a) warn: 'If the native aquatic fauna (within and outside) the current range of Bufo marinus is sero-negative to "ranaviruses", then the transmission of a pathogenic virus(es) could signal a significant environmental problem' (p. 7). See also Zupanovic et al. 1998b).

Microsporidia occurred as hyperparasites of Balantidium and a trematode (Delvinquier \& Freeland 1988). From Bufo marinus Paperna \& Lainson (1995) described a previously unrecorded microsporidian genus and species (Alloglugea bufonis), paying attention to 
its routes of infection in tadpoles and post-metamorphosis toads.

Abnormalities. In 1999, 4 juveniles born in our facilities had only 1 eye. We followed their development over months and could not detect any handicaps in terms of prey-catching success or growth rates. Finally, at a body size of $2.7 \mathrm{~cm}$, they were released into a pond of IR Land. We have never seen them again.

In 2002 several juvenile toads had green areas (spots, lines) on their backs. This abnormal colour pattern persisted in 2003.

Both tadpoles and juveniles exhibited considerable individual differences in growth rates and body sizes at a given age. In larger groups (40 and more individuals) there were always a few 'giants' and 'dwarfs'. The latter have rather limited survival chances, especially under field conditions. Apparently it is too late for them to build up sufficient energy reserves for over-wintering.

All 3 abnormalities seemed to have a genetic basis.

It is well known that amphibians are capable of regenerating fully grown lost limbs. However, to our knowledge it is not known whether a fully grown tail of a tadpole can be regenerated, nor to what extent the loss of a tail (which reportedly serves as a reservoir for material and energy required during metamorphosis) can affect the process of transforming a tadpole into a young toad - a process during which no food can be taken up. One of our tadpoles, ready to metamorphose, accidentally lost ca. $90 \%$ of its tail when we tried to catch it. We transferred the injured tadpole to a separate container and daily checked its condition. The toad was not able to regenerate the tail. Comparing the progress achieved in metamorphosis with that of toads kept in a neighbouring aquarium we could not detect any differences. Hence it must have been possible for the toad to fuel its metamorphosis from other body reserves.

Over-wintering. We have over-wintered toads (beginning in October/November) in our laboratories (Fig. 1). They were accommodated in breeding enclosures (Fig. 2). These were placed on tables in our labs together with smaller terraria and aquaria (Fig. 3). For over-wintering we covered part of the land areas in the enclosures with handfuls of moist moss, dead leaves and/or cut-off dry grass and reduced the water height to $4 \mathrm{~cm}$. The room temperature was slowly lowered and then maintained between 4 and $7^{\circ} \mathrm{C}$. At these temperatures the toads no longer move about; they substantially reduce their metabolism and hide practically motionless underneath the cover.

For another method of over-wintering we used plastic boxes (ca. 35 by $30 \mathrm{~cm}$ and $30 \mathrm{~cm}$ high; 4 or 5 toads per box) with perforated lids. The boxes were tilted about $4^{\circ}$ and filled with ca. $300 \mathrm{ml}$ of water. In the higher parts of the boxes we added a ca. $15 \mathrm{~cm}$ thick layer of loose moss. The boxes were then placed in a refrigerator adjusted to $7^{\circ} \mathrm{C}$. In one case the tempera-

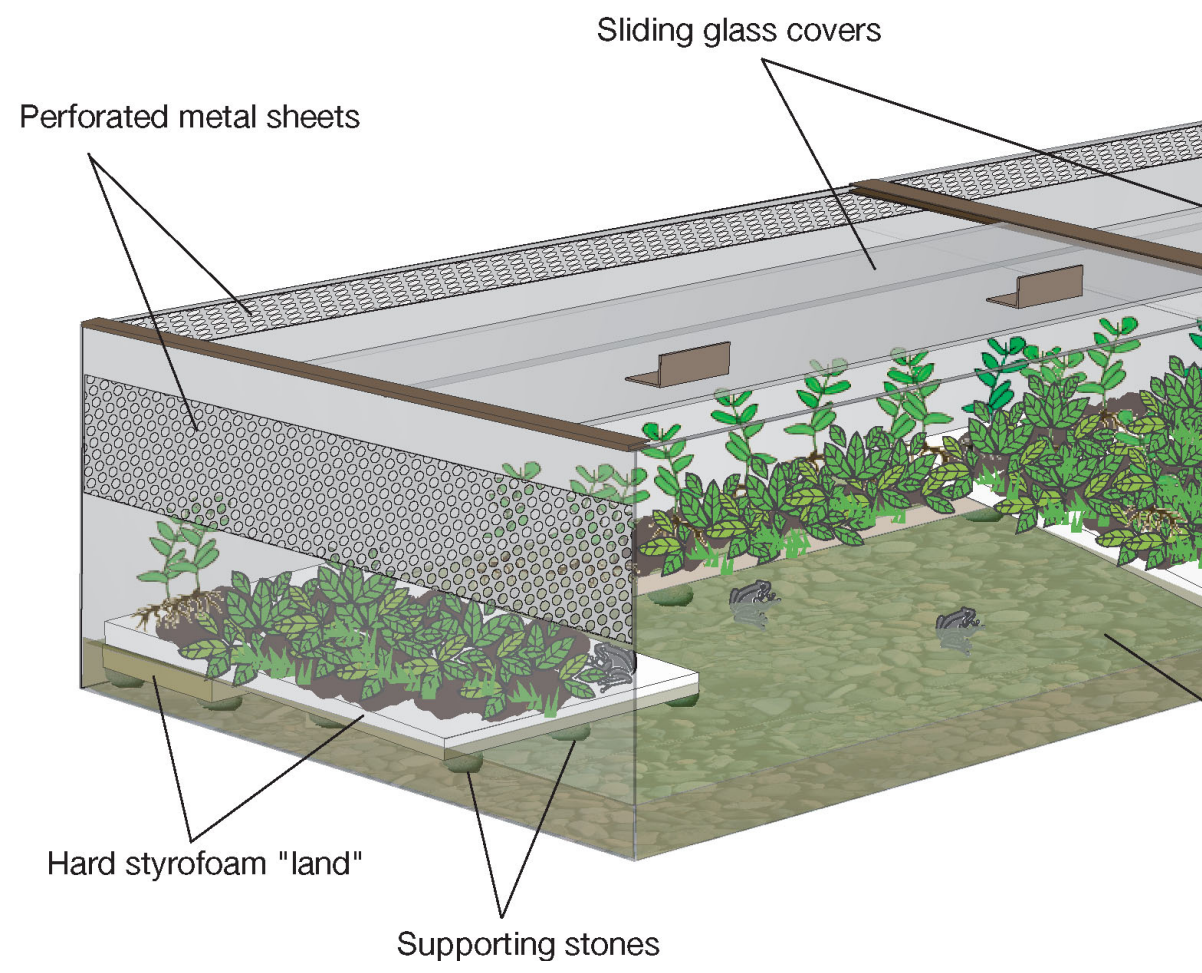

Supporting stones

Fig. 2. Breeding enclosure. Schematic view of essential features 


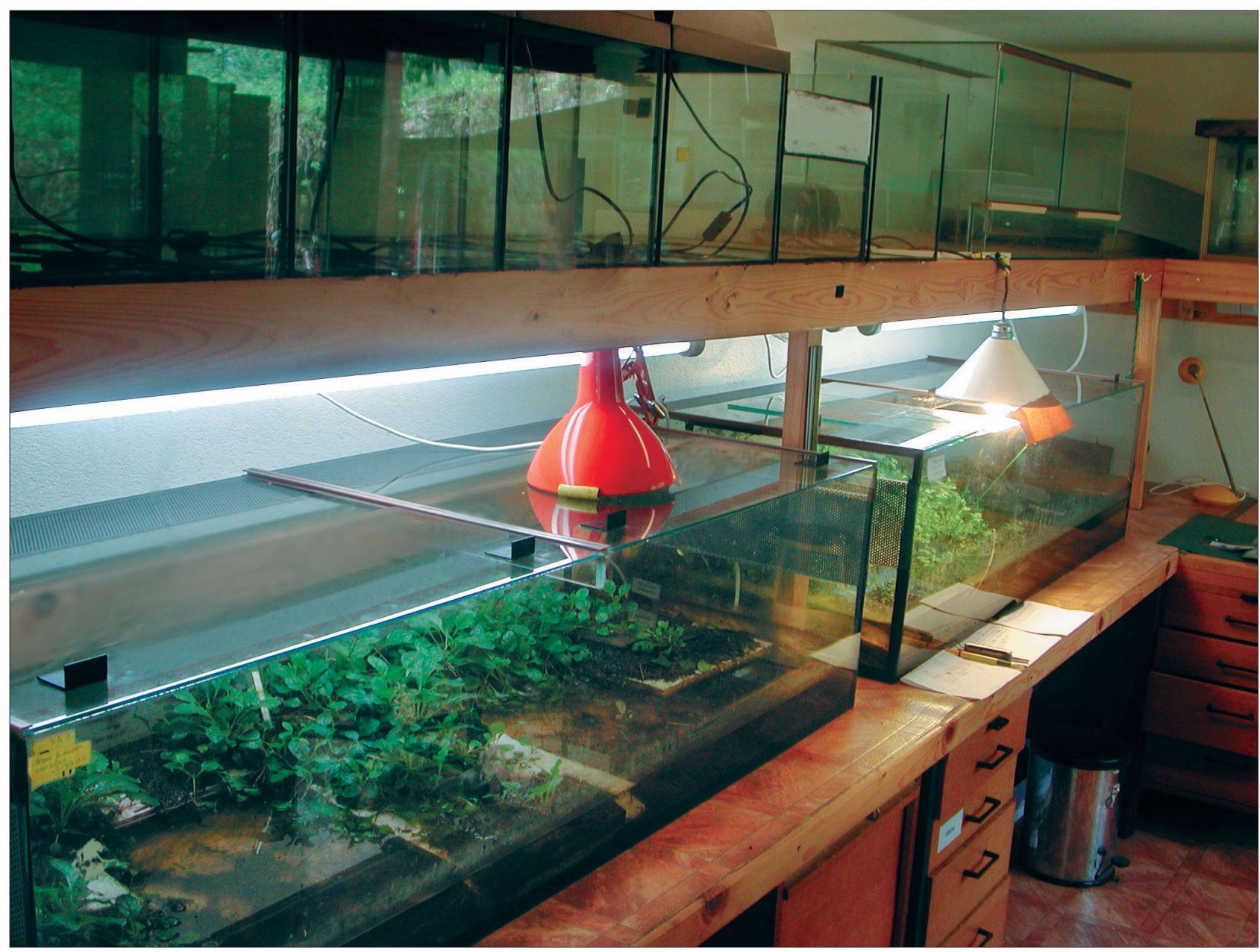

Fig. 3. Arrangement of breeding enclosures in Laboratory 2

ture control failed for 1 or 2 days and, at $-4^{\circ} \mathrm{C}$, all toads in the box died. We have also placed the plastic boxes in a large walk-in freezer. In all cases-except for the temperature-control failure $-100 \%$ of our overwintered toads survived.

We believe that over-wintering in the breeding enclosure provides the most suitable conditions for our toads.

Wake-up. The wake-up procedures practised with our laboratory toads in spring follow a standard procedure: Over 2 weeks, we gradually raise the room temperature to 8 or $9^{\circ} \mathrm{C}$. Soon the first toads begin to move about. After several days at $10^{\circ} \mathrm{C}$, practically all toads regain normal levels of locomotor activity*. They search for food or a place to take a sun bath. The awak-

\footnotetext{
*In addition to individual variation, thermal limits depend on previous thermal history (status of adaptation). For example, toads coming out of winter rest have lower thermal limits for initiation of movement than warm-adapted summer toads have for terminating their locomotion activities
}

ening migration drive always leads several individuals to forcefully attempt to escape from the enclosure. For up to weeks, most over-wintered toads tend to aggregate underneath a light source forming clusters, often sitting on top of each other (Fig. 4): they absorb heat and light.

\section{BREEDING}

The term 'breeding' refers to the period from egg fertilisation to larval hatching. The breeding process includes copulation, egg deposition and fertilisation, as well as embryonic development. It took us a while to develop laboratory breeding enclosures that can adequately accommodate the toads, are easy to construct and practical to use. And it required some experimenting to create quasi natural habitats and to control predators introduced with food and plants.

Breeding enclosures. The most successful enclosure type (selected after 2 years of experimenting) is illus- 


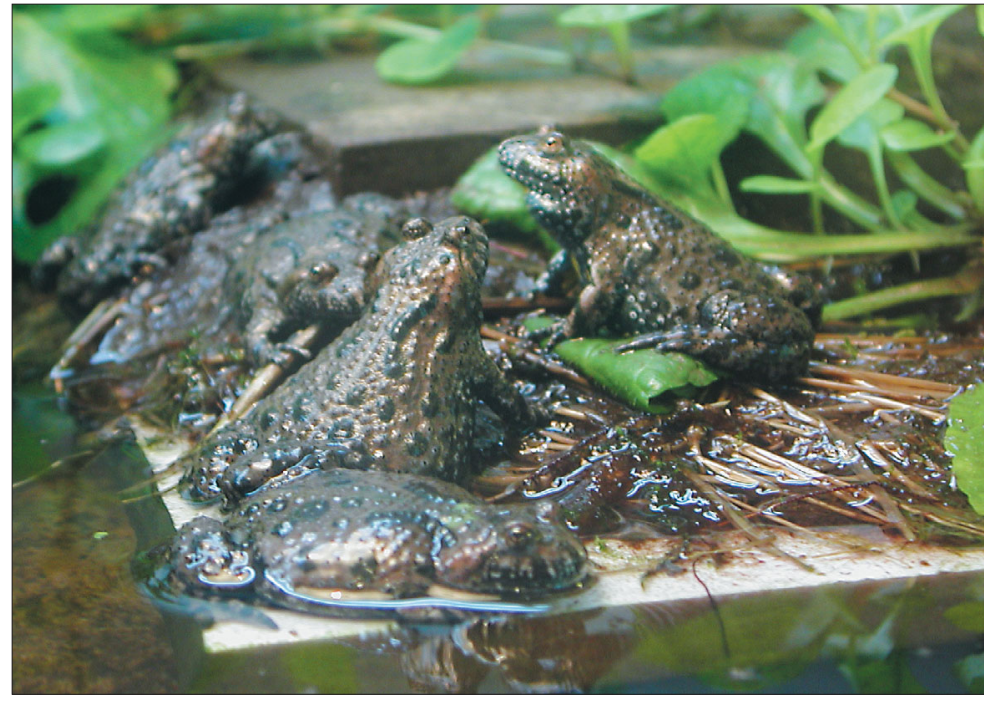

Fig. 4. Bombina bombina. 8 days after 'wake-up'. The toads aggregate underneath a light source forming clusters

trated in Figs. $2 \& 3$. It consists of glued-together glass plates $(150 \mathrm{~cm} \times 60 \mathrm{~cm} \times 60 \mathrm{~cm}$ high). The cover features a firmly attached back plate and 2 movable front plates. Each of the front plates can be slid back (by glued-on handles) in tracks, tightly fitting over the back part. Pushing back both front plates makes the whole interior of the enclosure easily accessible. For air exchange the upper part of the back plate and the upper parts of both side plates carry perforated metal sheets measuring on both container sides $60 \mathrm{~cm} \times 15$ $\mathrm{cm}$; on the back side: $150 \mathrm{~cm} \times 15 \mathrm{~cm}$ (Fig. 2). The perforations in the sheets have a diameter of $2 \mathrm{~mm}$.

Breeding habitats. We subdivided each breeding enclosure into 2 small habitats, each with a land and water area. The land area consisted of plant-covered slices of earth cut out from a nearby meadow. The slices were placed on hard Styrofoam plates. Height and angle of the plates were adjusted by stones of different sizes placed beneath the plates (Figs. $2 \& 3$ ). At parts of the boundary between land and water we positioned partially submerged cut-outs of grass and rush carpets, and in the water a few water plants (branches of Elodea canadensis or Ceratophyllum demersum). The space underneath the Styrofoam plates and the plants provided hiding places for the toads. In general, land height increased towards the back of the enclosure, thus offering to the toads land portions of varying wetness or dryness. On the higher land areas a variety of small plants grew. For egg attachment it is important that some blades and stems of grass or rush are submerged.

Inducing breeding. In order to induce breeding we further increased the room temperature to between 16 and $18^{\circ} \mathrm{C}$, prolonged the daylight periods in accordance with outside conditions and increased the amount of food. Starting in late April or early May, the temperature was further elevated to about 18 to $21^{\circ} \mathrm{C}$ during the day (about 15 to $16^{\circ} \mathrm{C}$ at night). As soon as insects appeared on IR Land we began catching 'meadow plankton' (free-living, mostly flying, insects) to supplement the toads' diet. We caught the insects by wielding a long-handled net over flowers, bushes and low tree branches.

Food. Our toads eat a large variety of small, moving animals. Non-motile or dead animals are not touched. The toads like insects, such as flies: Drosophila (fruit fly) and Musca domestica (house fly) and their motile larvae, butterflies and their hairless larvae, Metrioptera roeselli (Heuschrecke; bush cricket), Acheta domesticus (Heimchen; house cricket), Gryllus campestris (Feldgrille; field cricket); mollusks such as snails (removed from their shells or Nacktschnecken; slugs); worms, such as Lumbricus sp. (Regenwürmer; earthworms), Enchytraeidae (aster worms).

During the cold season, when most of these animals are not available in IR Land, we buy Acheta sp., Gryllus sp., Drosophila sp. or Musca sp. from a zoo shop. However, as soon as possible we collect food animals in IR Land. When zoo shop food and IR land food were

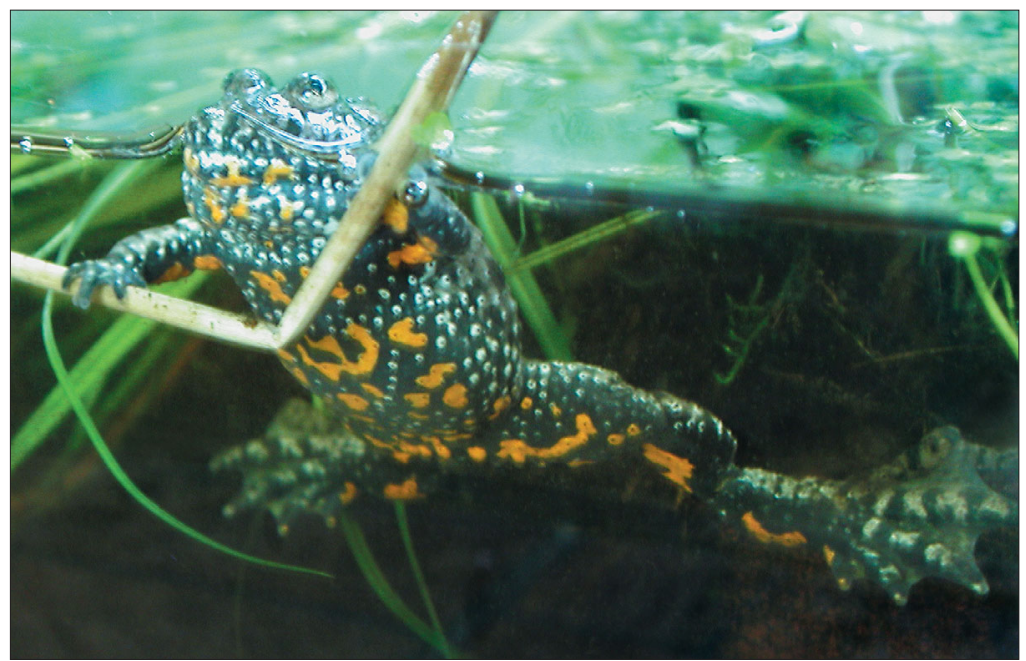

Fig. 5. Bombina bombina. Typical colouration of laboratory individuals 


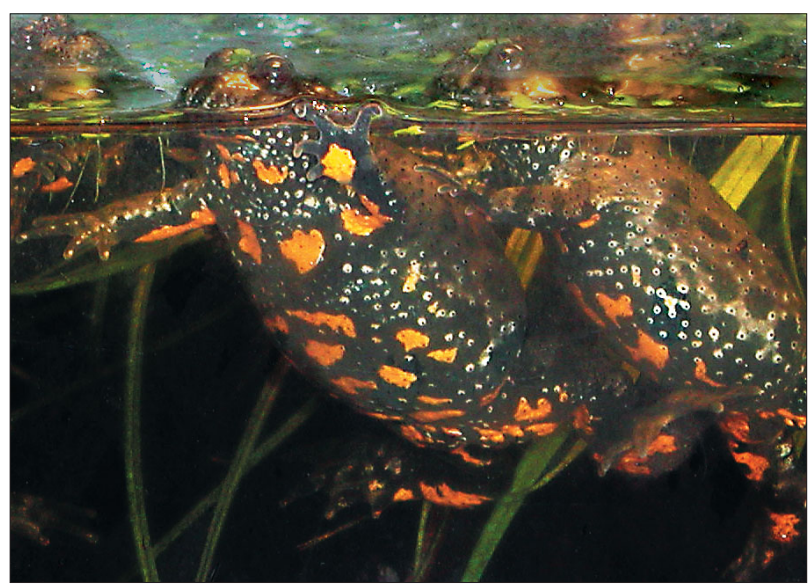

Fig. 6. Bombina bombina. Colouration of individuals in an outdoor enclosure

offered simultaneously the toads usually preferred the latter. Unconsumed or dead food is eaten by snails. Hence, a certain number of snails is considered useful.

Breeding populations. Our laboratory breeding populations did not have bright red, but orange or yellowish colour patterns on their bellies (Figs. $5 \& 6$ ). Colour variation is not unusual in Bombina bombina. While the kind of food offered may, to a limited extent, affect belly colours, primarily yellow bellies were found also in our field populations. Hence the coloration was presumably determined genetically. Apparently also genetically fixed were green spots or areas on head, neck and upper body in up to ca. $8 \%$ of the toads in one laboratory bred line of the third laboratory generation.

We placed in each breeding enclosure 2 adult males and 3 to 5 females. Adult size of Bombina bombina (snout tip to cloaca) ranges from 3.7 to slightly above $5 \mathrm{~cm}$.

In late spring or beginning summer, the males occupy one of the 2 water areas and defend it as their territory. Much of the time red-bellied toads float at the water surface, all 4 extremities widely spread apart. Upon disturbance, they quickly dive and flee to a hiding place or attempt to bury themselves in bottom mud. The structure and colour of their back provide excellent camouflage (Fig. 4). In May/June-provided they are in the right mood, and temperature and light conditions are suitable-the males begin to attract females by their oop-oop-oop-oop concert. Such calling can sometimes be stimulated by sprinkling water over the enclosure inside, using a watering can (simulation of rain) or via a hose ending in the water area (simulation of high-water events in nature). Both methods of adding water stimulate sexual activities of the toad.

Listening to the calling, often for hours, the 'ladies' approach without hurry and examine the situation. If they don't like the place or the male they leave again. We have never seen a male trying to interfere with the exodus of its potential bride. Partner selection is female dominated.

Breeding procedures. Timing and intensity of mating call activities underlie substantial variations. In general, males started to call in May and continued with pauses of varying lengths - through June and July (sometimes into August). While we have heard calls at daytime temperatures of 13 to $16^{\circ} \mathrm{C}$, major call activities were recorded at 20 to $25^{\circ} \mathrm{C}$. No males were heard to call above $32^{\circ} \mathrm{C}$. These temperature limits for call activities compare quite well with those reported earlier by Lörcher (1969); lower limits: 12.5 to $13.5^{\circ} \mathrm{C}_{\text {; }}$ upper limits: 30 to $34^{\circ} \mathrm{C}$. Usually there are several (3 to 5) distinct call periods in one season, each lasting one to several days. The call periods tend to decrease in length as the season proceeds. They are separated from each other by no-call periods of several days to weeks.

Females seem to be capable of discriminating not only between calls of con-specifics and those of other amphibian species, but also between calls from different con-specific male individuals. Thus mating calls assist in partner selection and serve as a genetic isolation mechanism (preventing or reducing hybridisation, i.e. mating between closely related species such as Bombina bombina and B. variegata).

The minimal territory size for calling males ranges between 30 and $60 \mathrm{~cm}$ in diameter. In our laboratory breeding enclosures, the males readily accepted a distance between the centres of 2 adjacent territories of some $60 \mathrm{~cm}$ without pronounced territorial conflicts. Field observations have shown that calling males may 'reside' far apart from each other (up to several hundred meters).

According to our laboratory observations, which require verification, nearby territories are not only marked by calling, but also by intense but apparently soundless throat movements and/or body vibrations and leg kicking (flailing). These male activities cause concentric water disturbances or waves of different intensities. They seem to be recognisable by nearby females and males.

Copulation and egg deposition can proceed without prior calling. This does not seem rare in females full of eggs and ready to spawn, especially if they have lived close to their mates for a long period of time. The toads know each other and are ready to reproduce - without need for searching or extensive acoustic stimulation.

We have attempted to induce calling in the laboratory earlier than in the field by raising the temperature and increasing day lengths (using daylight-simulating bulbs) - with limited success. It seems there are additional timing forces at work, such as barometer 
changes, rain, thunderstorms or heavy winds (which may also influence laboratory-held toads).

In the field, heavy rain is well known to induce calling and copulation in Bombina bombina. Water filled bottom depressions that dried out and were therefore predator-free refill quickly after heavy rain. The newly formed pools augment the chances for tadpoles to complete their development prior to the next dry-out. We have observed repeatedly that even forthcoming rain can induce increased sexual activities, hours before the first drops fall: the toads appear to be able to sense future climatic events.

Copulation occurred mainly in June and July; sometimes into August. Eggs were preferably laid during quiet and low-light periods (late afternoon, night, early morning) at water temperatures between 16 and $25^{\circ} \mathrm{C}$. The females select the site for egg deposition. They prefer shallow water that is well lit at daytime and features abundant plant growth. The eggs are attached in batches to underwater structures near the water surface, preferably on blades or stems of grass or rush. In the absence of plants other structures may be accepted; in extreme situations the eggs may simply be dropped on the bottom.

Number of eggs per spawn and egg size. The number of eggs per batch can vary considerably. It primarily depends on female size and age. In 2001 we calculated for 20 adult females (3.9 to $5.0 \mathrm{~cm}$ body length) a mean number of 30.6 (range: 15 to 40 ) eggs. This value compares well with earlier data published by Rafinska (1991), who determined a mean number of 32.5 (and a mean diameter of eggs 'without jelly capsule' of 1.49 $\mathrm{mm}$ ) - also in line with our findings. Rafinska reports significant variations of egg size between different females. As in other amphibians, Bombima bombina egg number and size tend to increase with female age and size.

Our lab populations have produced eggs, with pauses of varying lengths, between 1 and 3 times per summer. In one case 4 egg layings (ovipositions) were seen in a single female. We consider 2 to 3 ovipositions per season normal. Such multiple spawning increases offspring survival chances in shallow, often temporary small pools. Guzik (1987) estimated that 1 Bombina bombina female can lay between 186 and 1236 eggs per season. Inducing oviposition by injecting gonadotrophin, Rafinska (1991) reports that single B. bombina females laid on average 446 (35 to 1102) eggs. Our lab females laid considerably fewer eggs, between 120 and 280 per season. In their third or fourth year, they were probably younger and smaller than the females studied by Guzik and Rafinska. Neither of these 2 authors provided information on female age or size.

Mortality of subadults. Mortality of sub-adult life stages underlies substantial variations. In contrast to field conditions, mortality of eggs, tadpoles and juveniles was low in the laboratory. In eggs it varied from 8 to $20 \%$ (19 data sets of 20 individuals each, recorded over 3 years); in tadpoles, from 4 to $7 \%$ (21 data sets of 80 individuals each, recorded over 4 years); in juveniles, it was $8 \%$ (one data set of 250 individuals). However, in cases of disease (e.g. infections by protozoans and/or fungi, the taxonomic identity of which we were unable to establish) $100 \%$ of the juveniles may die within 3 to 5 weeks. During their normal life span, adults are much less subject to mortality. Over several years we have recorded practically no mortality in our parent populations

Importance of outdoor conditions. After 5 years of experimenting with Bombina bombina an important insight manifested itself: laboratory conditions for breeding, rearing and raising were inferior to outdoor conditions. Outdoor toads tended to be more intensively coloured (Fig. 6) and more active; their calling period began earlier, in spite of lower temperatures, and their reproductive success was higher. Consequently, beginning in 1999, we transferred our laboratory breeding enclosures, during the warm season, to tables located outside of our laboratories. During the day they were exposed to both shade and sunshine (long, intensive sun exposure may lead to critical overheating of the water and to death at $38^{\circ}$ to $39^{\circ} \mathrm{C}$ ).

Within days-sometimes within hours-transfer outdoors induced calling, copulation and egg laying. During summer 2001 we collected about 1100 eggs from 3 females in one outdoor enclosure-more than we had ever obtained under comparable conditions in the lab. About 80 eggs remained in the enclosure and developed to tadpoles and juveniles, apparently with no negative influences from living closely together with their parents in a small space. Collected eggs were transferred to the lab where they developed and yielded 1070 juveniles.

We do not know the exact reasons for better development under outdoor conditions but hypothesise that light quality and intensity, wind (more intensive air exchange between outside and enclosure inside), rain (can drop through top metal perforations of outdoor enclosures) and acoustic as well as visual stimuli from the surrounding nature may have played a role.

Effects of extreme low temperature on sexual products. As already stated, timing and capacity of egg production vary considerably. They depend primarily on female age/size/condition, nutritional status and ambient temperature. Under extremely adverse conditions, egg laying can be entirely suppressed. While a brief cold spell had no demonstrable effect, a severe reduction of temperatures (to between 5 and $9{ }^{\circ} \mathrm{C}$ lasting some 8 days in May) had disastrous consequences: it caused a total blockage of egg production. When we 
realised that something might have gone wrong, we transferred 2 males and 6 females into normal annual temperature conditions provided in the laboratory. However, our rescue attempt did not re-activate egg laying. The cold damage turned out to be irreversible. We assume that the ripening process of sexual products was irreversibly interrupted, and that eggs and sperm were finally resorbed. In any case, the blockage resulted in the complete loss of a new generation. In a highly endangered species, such reproductive failure could significantly affect a regional population. Our inquiries confirmed a parallel complete reproductive failure in another toad population some $60 \mathrm{~km}$ away.

Egg development. Fertilised eggs develop quickly. This is an essential strategy for increasing survival chances in a species reproducing in unstable, often temporary water bodies. In the laboratory we kept freshly fertilised eggs at natural daily temperature fluctuations (open windows) in shallow plastic dishes filled 3 to $4 \mathrm{~cm}$ high with filtered pond water (June/ July). Temperatures ranged from 15 to $23^{\circ} \mathrm{C}$ during the day and 13 to $17^{\circ} \mathrm{C}$ during the night. Under these conditions the germinal disc stage was reached within 1 day, the earliest comma stage within 1.8 days. Embryo development was completed after 5 to 7 days. Larvae of one and the same batch did not hatch simultaneously; in exceptional cases the period between hatching of the first larvae and that of the last extended over 2 days or more.

In an early June 2003 experiment, from 30 freshly fertilised eggs 12 larvae hatched after 5.8 days (range: 5.2 to 6.5 days; temperature: $23^{\circ} \mathrm{C}$ day, $17.5^{\circ} \mathrm{C}$ night). With 18 eggs dying during the development, mortality was significantly higher than normal. The reason for this may have been that several eggs were covered by a film of blue-green algae. In a late June 2003 experiment, from 35 freshly laid fertilised eggs 25 larvae hatched after 5.7 days (range: 5 to 6 days; most of the rest during the next day $\left(22^{\circ} \mathrm{C}\right.$ day, $17.4^{\circ} \mathrm{C}$ night $)$; mortality was $3 \%$. While constant temperatures allow to obtain more precise values, they are unnatural and the resulting information may therefore not be well applicable to natural field-population dynamics. In a subsequent experiment involving a batch of 33 eggs, mortality was $9 \%$. At temperatures almost identical to the ones described above, development from fertilisation to hatching took between 6 and 8 days. The overall average time span (established over 5 years) from fertilisation to hatching is 6.2 days.

Life span. Bombina bombina have a long life expectancy. In our enclosures some toads lived at least 12 years. According to a toad-keeping colleague, $B$. bombina can attain an age of 20 years (Mencke personal communication). Since $B$. bombina begin to breed at an age of 3 years, during a presumed life span of 15 years breeding individuals can contribute to population strength over up to 12 seasons. Such high reproduction capacity is a basic prerequisite and an important ecological strategy for the survival of a species subjected to intensive predation, especially during larval and early juvenile life, and forced to exist in unstable environments.

\section{REARING}

'Rearing' comprises the developmental period between hatching of larvae and completion of metamorphosis (juvenile).

Larval development. Prior to hatching we transferred eggs into 501 outdoor aquaria (June to August) filled with filtered and gently aerated pond water. The aquaria had previously been exposed to natural light conditions for 2 weeks in order to induce and support microbial growth on walls and bottom. Sometimes we added a few Elodea or Myriophyllum branches. The total duration of larval life from hatching to the end of metamorphosis was 45 to 65 days $\left(23\right.$ to $26^{\circ} \mathrm{C}$ water temperature). However, a small fraction (ca. $4 \%$ ) of the larvae took more than 80 days. They remained abnormally small. Most of them eventually died. A comparable situation was observed by us also in other amphibians (newts) and in fish (carp).

Freshly hatched Bombina bombina larvae have a slightly curved body shape - a remnant of space limitations in the egg. They straighten quickly. In one group (30 larvae) total length (snout tip to tail end) at hatching was on average $7.2 \mathrm{~mm}$ (range: 6.2 to 8.6 $\mathrm{mm}$ ). In a second group (34 larvae) average hatching length was $6.9 \mathrm{~mm}$ range: 6.0 to 8.1). Over several years deviations from these values were small, in fact negligible for the purpose of the present paper.

In 30 Bombina bombina larvae kept at water temperatures between 23 and $26^{\circ} \mathrm{C}$ average body lengths were at Day 5: $11.8 \mathrm{~mm}$; Day 10: $13.7 \mathrm{~mm}$; Day 20: 19.4mm; Day 30: $29.6 \mathrm{~mm}$. At a given age tadpoles may differ considerably in body length.

Newly hatched larvae usually attach themselves vertically in a head-up position to solid surfaces (glass plates of the aquarium, leaves and stems of plants), or rest on the bottom. Unless disturbed, they remain more or less motionless for 2 to 3 days. During this resting period they consume their nutritional reserves and begin to grow.

Many freshly hatched larvae did not respond when carefully poked with the tip of a pipette. We could even push them away from their rest place without eliciting locomotor activities. They simply drifted motionless through the water before sinking to a new resting place. However, only hours later, upon disturbance, 
most larvae performed brief, erratic bursts of (rotating and spiralling) movements attaining considerable speed. After a burst they quickly attached themselves again and continued to rest. We have seen such sudden bursts to shock or confuse would-be predators (insect larva, fish); this behaviour can therefore be interpreted as self-protection. In many cases these earliest escape attempts were not necessarily directed away from the source of the disturbance. The first freeswimming larvae were observed 3 days after hatching. They now swam in a more regular pattern and upon disturbance performed less erratic and more directional escape movements. Overall, the larvae still preferred to rest attached to a firm surface.

Attached larvae are less likely to be subject to predation than swimming ones. Motionless attachment is an effective means of not arousing the interest of hunting predators. While early larvae hardly ever respond to the vibrations and noises in the lab, they can be shocked into dashing movements by pounding against the aquarium walls.

Control of larval predators. In the laboratory, major predators of Bombina bombina tadpoles are leeches and insects. In the field, $B$. bombina larvae, juveniles and adults are attacked by numerous predators; for details consult Report 5. In the laboratory, measures for excluding or controlling predators are: (1) check all material, especially plants, introduced from a pond or river; (2) examine the plants in shallow-water dishes using a binocular microscope; (3) always pour water to be added to culture enclosures through plankton gauze. Predator eggs and early larvae are difficult to detect. Hence it is necessary to continue the search for up-growing predators. A single undetected small leech can grow quickly to a body length of $3 \mathrm{~cm}$ and consume or kill 30 tadpoles within 2 weeks.

Food for larvae. Early larvae feed on the microbial films covering submerged surfaces. The films consist of an often complex microbial community composed mainly of bacteria and diatoms (e.g. Teissier \& Torre 2002, Lyautey et al. 2003, Pei Yuan Quian et al. 2003). Later, the larvae also graze on the often more speciesrich biota on water plants. Older larvae may accept commercially available vegetarian fish food (dried, ground), pulverised Urtica (Brennessel; nettles) and thin pieces of (slightly decaying) salad leaves. The first faeces strings began to leave the body of 4 day-old larvae.

Grazing mouth parts could be observed through a magnifying glass held close to an aquarium plate. Except for brief pauses (several minutes) grazing continued from now on throughout most of the remaining larval life. Even at night, when surprised by a sudden flashlight, several larvae were busily feeding. Indeed, the larvae behaved like feeding machines focussed on food intake and seemingly without interest in any other things of their environment, including predators. While protected in our labs, without any 'built-in' predator escape behaviour toad larvae are easy prey in nature.

As the larvae grew in size (ca. $15 \mathrm{~mm}$ total length) we offered them a variety of other potential food. They 'nibbled' on dead plant tissues and pieces of thin banana slices, but rejected most of our offerings. Koi and trout food pellets, containing both plant and animal material, caused a pronounced rejection gesture or even a brief flight response. Only after the pellets had fallen apart into small mounds of particles did the larvae show renewed interest, but they still did not feed. It took up to 10 days ( 20 to $25 \mathrm{~mm}$ total length) before some larvae began hesitatingly to graze on the pellets. We do not know whether they fed on the rapidly forming microbial surface film on the pellets or on the pellets themselves. Small white bread pieces, were at first ignored, but after 10 to 20 minutes attracted attention and the larvae began to graze on the bred surface. Sections of aquarium glass plates freshly submerged in water began after 30 minutes to attract the attention of larvae and were thereafter regularly used as new 'grazing ground'. Potential food is examined per mouth. Body contact with food did not elicit recognisable responses. After another 7 days (30 to $33 \mathrm{~mm}$ total length) newly provided koi pellets were-following softening - surrounded by a swarm of excited tadpoles eagerly and obviously feeding pellet material and pushing competitors away from their new food source.

In another group of up-growing larvae interest in koi and trout pellets developed later. Feeding on fallenapart pellets was definitely recorded only in larvae longer than $32 \mathrm{~mm}$. To larvae of $34 \mathrm{~mm}$ length or longer we began to feed pellets regularly (an aquarium with 25 larvae received 6 to 7 pellets up to 4 times a day). By heavy tail movements the tadpoles distributed pellet parts over the aquarium bottom. They fed on pellets more and more intensively. Five newly added pellets disappeared within 12 or 16 minutes. The larvae exhibited substantial growth rate increases after pellet consumption. However, it was not yet possible to use the pellets as sole food source. After feeding on pellets for an hour or so, the tadpoles turned away and fed on other food, such as decaying plants (Elodea, Myriophyllum, reed) or animals (decaying earthworms, insects). We had witnessed in still leg-less toad larvae the very first steps in the transition from a vegetarian into a meat eater.

Overall, in sharp contrast to the directional prey hunting and precise aiming in juvenile and adult toads, the food searching technique of larvae is based on random search. 
Begin of air breathing. Toad larvae began very early with air breathing in addition to gill breathing. At $22^{\circ} \mathrm{C}$ we observed a few larvae 8 days after hatching to approach the water surface and to gulp in air. Tadpoles of $2.5 \mathrm{~cm}$ total length (snout tip to tail end) suddenly darted to the water surface, often releasing an air bubble on their way up and then, after reaching the surface, rapidly gulping in new air. This marked the start of regular air breathing. With progressing leg formation, air breathing became more pronounced. At temperatures above $24^{\circ} \mathrm{C}$, air breathing of 4-legged tadpoles occurred every 8 to 12 minutes.

In contrast to general opinion, toad larvae did not avoid water movement. Some even actively approached the stream of air bubbles and the water currents caused by aeration. And they seemed to enjoy that. The defensive 'playing dead' response-well known from adult toads reacting to heavy disturbance - began to develop already in some 2- or 4-legged tadpoles.

Metamorphosis. The transition from tadpole to juvenile toad begins when the larvae reach a total body length of 3.8 to $4.8 \mathrm{~cm}$ (depending on genetic factors, nutritional status, temperature). At first, hind-leg buds appear and then rapid leg growth begins. Following the sudden appearance of front legs (which had developed hidden in the gill chamber) the very first steps of tail absorption start. Metamorphosis is normally completed no later than August. It involves dramatic changes in morphology, physiology and behaviour. In metamorphosing tadpoles, mouth and intestine are restructured and feeding is interrupted. Arms and legs begin to function as soon as they appear. A brief period of combined tail and limb use is followed by a complete shift from tail to leg propulsion (swimming, walking, jumping). The head form changes and so does the structure and function of mouth parts, intestine and eyes.

Early 4-legged tadpoles begin to show interest in shallow water areas or seek the neighbourhood of Styrofoam plates offering an ascend to resting places above the water surface. Increasingly, metamorphosing individuals explore moist land, often with their tail still at almost full length. With the normal tail lengths reduced by only 10 to $20 \%$, some tadpoles climb small plants and begin to jump after insects (July, midAugust).

\section{RAISING}

'Raising' comprises the period between end of metamorphosis and attainment of sexual maturity. Bombina bombina complete metamorphosis at an age of 2 to 2.5 months (end of June to mid-August). Freshly metamor- phosed juveniles have a body length (snout tip to cloaca) of 12 to $18 \mathrm{~mm}$. Adult total body length ranges from $3.8 \mathrm{~cm}$ to slightly above $5 \mathrm{~cm}$ (final size). Sexual maturity is usually attained at a body length of about $4 \mathrm{~cm}$ and an age of 3 years.

As raising enclosures for groups of juvenile Bombina bombina we mostly used terraria $(60 \mathrm{~cm} \times 30 \mathrm{~cm} \times$ $30 \mathrm{~cm} \times$ high; Fig. 3, upper row) topped by an easily removable wooden frame covered by insect gauze. This cover facilitated aeration and access for feeding, and it prevented the escape of food animals.

Food. Juvenile toads were first fed small, non-flying Drosophila (fruit flies; Fliegen) and freshly hatched crickets (Grillen); both are available at zoo shops. The juveniles very quickly learn to hunt their prey on the water surface, on land and on plants (we have never seen Bombina bombina to hunt underwater). They jump powerfully, far and high, taxing distance and direction in seconds, and soon (after hours or days) attain near $90 \%$ catching successes. Even in seemingly 'impossible' situations they manage to sort out approach possibilities and successfully catch their food. They have a fantastic appetite and, at higher temperatures, should be fed once or twice per day.

Juveniles were offered increasingly larger prey, such as young crickets (Heimchen, Grillen), house flies (Hausfliegen), worms (Würmer), hairless insect larvae, and, of course, 'meadow plankton' (see above). Adult toads have a wide food range. They swallowed practically all animals we caught for them in IR Land, including long-legged spiders (Spinnen), large worms (Würmer), butterflies (Schmetterlinge), grasshoppers (Heuschrecken), and in one case also bees (Bienen) and wasps (Wespen). Hungry adults catch and may swallow compact prey up to a size not much smaller then themselves and worms 2 or 3 times their body length. Again: only moving prey is attacked or resting prey that shows some activity such as breathing or movements of antenna or limbs. The toads consume flying, creeping or gliding prey, and all sorts of animals fallen on the water surface. Food diversity is essential for normal development. The quality of the food is examined in the mouth cavity. Unpalatable food is energetically spit out.

Pre-copulating toads usually do not separate for feeding. They may even catch different ends of the same worm. Who ultimately wins is not a matter of 'politeness', but a matter of power.

The frequently made statement that red-bellied toads hunt exclusively or predominantly on or in water is false. They make extensive foraging trips over land. The general rule is: the toads are where their food is.

Release into Inter-Research Land. IR Land is located in the valley of the river Luhe near the village of Oldendorf/Luhe, Germany. It comprises ca. $55000 \mathrm{~m}^{2}$. The 
authors have modified the original meadow landscape with the aim of providing suitable habitats for amphibians (and other rare animals and plants). For details consult Kinne et al. (2003, Fig. 1.) From 1998 to 2002 we released 1855 laboratory-bred juveniles and hundreds of tadpoles into small pools. Release activities continue at this writing (2003). Several of the juveniles released by us attained sexual maturity and began to reproduce. So the first steps in building up a self-supporting field population can be considered a success.

\section{CONCLUSIONS AND FUTURE PLANS}

After investing much effort in breeding, rearing and raising Bombina bombina, and after releasing thousands of juveniles in IR Land we were looking forward to seeing them again and to hearing a forceful oopoop-oop-oop concert. We have been disappointed. Over the last few years we saw only few toads and heard toad calls only occasionally. The toads are genetically programmed to search for and occupy new habitats throughout their life. In fact, the urge of $B$. bombina to migrate is enormous. We decided not to interfere with the toads' emigrations. After all they may find new supporting habitats and thus enlarge their overall distribution area. Since we do not intend to restrict the migrations of IR Land animals, we must expect further large losses in the future. When you have made the decision to support endangered life you must be prepared to accept disappointments. You need a lot of patience. The ways of nature - not least those of a nature deformed by Homo sapiens - are not easy to influence or to 'correct'.

In the future we plan to build additional shallow toad pools in areas without large trees and to keep those areas free of newly growing larger plants. Bombina bombina prefer open areas. Trees and bushes in the Luhe valley (e.g. alder (Erlen), birches (Birken), oak (Eichen), beech (Buchen), nuts (Nüsse) have enormous reproductive potentials. Unless we permanently interfere most of IR Land would soon be a forest.

Acknowledgements. Our work was financed by InterResearch. Based on our plans, the firm Burmester (Hamburg) built the first breeding enclosures. Professor Tom Berman (Kinneret Limnological Laboratory, Israel), provided important information, especially on amphibian diseases. John Austin (IR) illustrated and Matthias Seaman (IR) copy-edited our text. We are grateful for all this help.

\section{LITERATURE CITED}

Ahne W, Bremont M, Hedrick RP, Hyatt AD, Whittington RJ (1997) Iridoviruses associated with epizootic haematopoi- etic necrosis (EHN) in aquaculture. World J Microbiol Biotechnol 13:367-373

Berger L, Speare R, Daszak P, Green DE and 10 others (1998) Chytridiomycosis causes amphibian mortality associated with population declines in the rain forests of Australia and Central America. Proc Natl Acad Sci USA 95: 9031-9036

Bradley GA, Rosen PC, Stredl MJ, Jones TR, Longcore JE (2002) Chitridiomycosis in native Arizona frogs. J Wildl Dis 38:206-212

Clark HF, Brennan JC, Zeigel RF, Karzon DT (1968) Isolation and characterization of viruses from the kidneys of Rana pipiens with renal adenocarcinoma before and after passage in the red eft (Triturus viridescence). J Virol 2: $629-640$

Clark HF, Gray C, Fabian F, Zeigel R, Karzon DT (1969) Comparative studies of amphibian cytoplasmic virus strains isolated from the leopard frog, bullfrog, and newt. In Mizell M (ed) Biology of amphibian tumours. SpringerVerlag, Berlin, p. 310-326

Cunningham AA, Langton TES, Bennett PM, Drury SEN, Gough RE, Kirkwood JK (1993) Unusual mortality associated with poxvirus-like particles in frogs (Rana temporaria). Vet Rec 133:141-142

Darlington RW, Granoff A, Breeze DC (1966) Viruses and renal carcinoma in Rana pipiens II. Ultrastructural studies and sequential development of virus isolated from normal and tumor tissue. Virol 29:149-156

Darlington RW, Granoff A, Came PE, Breeze DC (1966) Viruses and renal carcinoma of Rana pipiens. I. The isolation and properties of virus from normal and tumor tissue. Virology 29:133-148

Delvinquier BLJ, Freeland WJ (1988) Protozoan parasites of the cane toad, Bufo marinus, in Australia. Aust J Zool 36:301-316

Drury SEN, Gough RE, Cunningham AA (1995) Isolation of an iridovirus-like agent from common frogs (Rana temporaria). Vet Rec 137:72

Engel H (1985) Untersuchungen zur Ökologie an einer Population der Rotbauchunke, MS Thesis Univ. Hamburg

Fijan N, Matasin Z, Petrinec Z, Valpotic I, Zwillenberg LO (1991) Isolation of an iridovirus-like agent from the green frog (Rana esculenta L). Vet Arch Zagreb 3:151-158

Gliwicz ZM (2003) Between hazards of starvation and risk of predation: the ecology of offshore animals. In: Kinne O (ed) Excellence in ecology, Book 12. International Ecology Institute, Oldendorf/Luhe

Granoff A, Came PE, Breeze DC (1966) Viruses and renal carcinoma of Rana pipiens.I. The isolation and properties of virus from normal and tumor tissue. Virology 29:133-148

Granov A (1989) Viruses of Amphibia: a historical perspective. In: Ahne W, Kurstak E (eds) Viruses of lower vertebrates. Springer-Verlag, Berlin, p. 3-12

Guzik M (1987) Morphology of the generative system and the number of eggs produced by the fire-bellied toad Bombina bombina (L.) (in Polish with English summary). Prace zoologiczne (Wyzsza Szkola Pedagogiuczna, Krrrak0w) 5:23-35

Hengstberger SG, Hyatt AD, Speare R, Coupar BEH (1993) Comparison of epizootic haematopoietic necrosis and Bohle iridoviruses, recently isolated Australian iridoviruses. Dis Aquat Org 15:93-107

Kinne O (1956) Über den Einfluß des Salzgehaltes und der Temperatur auf Wachstum, Form und Vermehrung bei dem Hydroidpolypen Cordylophora caspia (PALLAS), Athecata, Clavidae. I. Mitteilung über den Einfluß des Salzgehaltes auf Wachstum und Entwicklung mariner, 
brackischer und limnischer Organismen. Zool. Jb. (Physiol.) $66: 565-638$

Kinne O (1958) Über die Reaktion erbgleichen Coelenteraten-Gewebes auf verschiedene Salzgehalts- und Temperaturbedingungen. II. Mitteilung über den Einfluß des Salzgehaltes auf Wachstum und Entwicklung mariner brackisher und limnischer Organismen. Zool. Jb. (Physiol.) 67:407-486

Kinne O (1988) Eco-Ethics International Union (EEIU): Humanity can survive only with a new concept of ethics: ecoethics. EEIU Brochure (Original), Inter-Research, Oldendorf/Luhe

Kinne O (2002) Öko-Ethik weiterentwickelter Text: 01.01.2001. EEIU Brochure, Inter-Research, Oldendorf/Luhe

Kinne O (2003a) EEIU: Local diversity embedded in global unity. ESEP 2003:81

Kinne O (2003b) Endangered species research 1: The essence of IR involvement. Inter-Research Reports 1:1-2

Kinne O, Kunert J, Zimmermann W (2003) Endangered species research 2: Land and equipment. Inter-Research Reports 2:1-3

Lyautey E, Teissier S, Charcosset J-Y, Rols J-L, Garabe'tian F Bacterial diversity of epilithic biofilm assemblages of an anthropised river section, assessed by DGGE analysis of a 16S rDNA fragment Aquat Microb Ecol 33:217-224

Lörcher K (1969) Vergleichende bio-akustische Untersuchungen an Rot- und Gelbbauchunken, Bombina bombina (Linnaeus) und Bombina variegata (Linnaeus). Oecologia 3:84-124

Paperna I, Lainson R (1995) Alloglugea bufonis nov. gen., nov. sp. (Microsporea: Glugeidae), a microsporidian of Bufo marinus tadpoles and metamorphosing toads (Amphibia: Anura) from Amazonian Brazil. Dis Aquat Org 23:7-16

Pascolini R, Daszak P, Cunningham A A, Tei, S, Vagnetti D, Bucci S, Fagotti A, Rosa I Di (2003) Parasitism by Dermocystidium ranae in a population of Rana esculenta complex in Central Italy and description of Amhibiocystidium n.gen. Dis aquat Org 56:65-74

Qian P-Y, Thiyagarajan V, Lau SCK, Cheung SCK Relationship between bacterial community profile in biofilm and attachmentr of the acorn barnacle Balanus amphitrite. Aquat Microb Ecol 33:225-237

Rafinska A (1991) Reproductive biology of the fire-bellied toads, Bombina bombina and B. variegata (Anura: Discoglossidae): egg size, clutch size and larval period length differences. Biol J Linnean Soc 43:197-210

Speare R (1990) A review of the diseases of the cane toad, Bufo marinus, with comments on biological control. Aust Wildl Res 17:387-410

Speare R, Freeland WJ, Bolton SJ (1991) A possible iridovirus in erythrocytes of Bufo marinus in Costa Rica. J Wildl Dis $27: 457-462$

Speare R, Smith JR (1992) An iridovirus-like agent isolated from the ornate burrowing frog Limnodynastes ornatus in northern Australia. Dis Aquat Org 14:51-57

Teissier S, Torre M (2002) Simultaneous assessment of nitrification and denitrification on freshwater epilithic biofilms by acetylene block method. Water Res 36:3803-3811

Whittington RJ, Speare R (1996) Sensitive detection of serum antibodies in the cane toad Bufo marinus. Dis Aquat Org 26:59-65

Wilkens H (1979) Die Amphibien des mittleren Elbetals: Verbreitung und Ökologie der Rotbauchunke. Natur und Landschaft 54 (2):46-50

Willis DB, Goorha, R, Miles M, Granoff A (1977) Macromolecular synthesis in cells infected by frog virus 3 . VII. Transcriptional and post-transcriptional regulation of virus gene expression. J Virol 24:326-342

Woodhams DC, Alford RA, Marantelli G (2003) Emerging disease of amphibians cured by elevated body remperature. Dis Aquat Org 55:65-67

Zupanovic Z, Lopez G, Green B, Bartran G, Parkes H, Whittington RJ, Speare R, Hyatt AD (1998a) Giant toads Bufo marinus in Australia and Venezuela have antibodies against 'ranaviruses'. Dis Aquat Org 32:1-8

Zupanovic Z, Musso,C, Lopez G, Louriero CL, Hyatt AD, Hengstberger S, Robinson AJ (1998b). Isolation and characterization of iridoviruses from the giant toad Bufo marinus in Venezuela. Dis Aquat Org 33:1-9

\section{ENDANGERED SPECIES RESEARCH}

Number 4: Successful re-introduction of the newts Triturus cristatus and T. vulgaris 